\title{
Pluralismo jurídico em África: Ficção ou realidade?
}

Legal Pluralism in Africa: Fiction or Reality?

Pluralisme juridique en Afrique: Fiction ou réalité?

\section{Sara Araújo}

\section{(2) OpenEdition}

\section{Journals}

Edição electrónica

URL: http://journals.openedition.org/rccs/468

DOI: $10.4000 /$ rccs.468

ISSN: 2182-7435

\section{Editora}

Centro de Estudos Sociais da Universidade de Coimbra

\section{Edição impressa}

Data de publição: 1 Dezembro 2008

Paginação: 121-139

ISSN: 0254-1106

Refêrencia eletrónica

Sara Araújo, « Pluralismo jurídico em África: Ficção ou realidade? », Revista Crítica de Ciências Sociais [Online], 83 | 2008, colocado online no dia 01 dezembro 2012, criado a 19 abril 2019. URL : http:// journals.openedition.org/rccs/468; DOI : 10.4000/rccs.468 


\section{LEONOR LIMA TORRES JOSÉ AUGUSTO PALHARES}

\section{Cultura, formação e aprendizagens em contextos organizacionais}

Das correntes de cariz mais tecnocrática e gerencialista às perspectivas de natureza mais crítica, o enfoque nos domínios simbólicos das organizações emerge como um denominador comum, uma espécie de pano de fundo que mapeia e define as potencialidades e os limites do desenvolvimento estratégico das organizações de trabalho. Partindo de um enfoque crítico e reflexivo sobre a problemática dos recursos humanos, o artigo debate a importância dos processos de educação não-escolar (não-formais e informais) na construção de aprendizagens culturais múltiplas e na sedimentação de culturas e identidades organizacionais. O cruzamento entre estes dois campos de estudo sugere novas pistas ao nível da acção organizacional, designadamente nos domínios das estratégias e modalidades de formação e de educação de adultos, dos processos de socialização e integração dos actores, das esferas da comunicação e das novas tecnologias, da redefinição dos perfis e desempenhos profissionais, entre muitas outras áreas estratégicas de intervenção organizacional.

Palavras-chave: cultura organizacional, aprendizagem cultural, educação não-escolar, educação, formação.

\section{Introdução}

Entre a multiplicidade de temáticas que estruturam o campo da sociologia das organizações, a aprendizagem cultural aparece frequentemente como um adereço de outras problemáticas consideradas centrais e teoricamente mais relevantes. A natureza já de si ambígua do conceito de aprendizagem, associada ao significado plurifacetado da noção de cultura, abriu caminho ao despontar de análises algo incertas e teoricamente fragmentadas.

É nosso objectivo, neste trabalho, propor um olhar sobre este tema a partir da articulação entre dois enfoques disciplinares: o primeiro, situado no campo de uma sociologia da educação, privilegiará uma análise das especificidades dos espaços-tempos de educação não-formal e informal (Palhares, 2004); o segundo, decorrente de uma sociologia das organizações, 
enfatizará os processos de construção cultural nos contextos organizacionais (Torres, 2004). O cruzamento entre estes dois enfoques com distintas tradições teóricas e metodológicas permite destacar a relevância dos processos de aprendizagem cultural na construção da cultura e das identidades organizacionais, sobretudo quando desenvolvidos em contextos de educação e de formação não-escolares. Por outro lado, é igualmente pertinente verificar de que modo a especificidade cultural de uma determinada organização pode condicionar os processos de aprendizagem cultural, facilitando ou dificultando a experienciação de modalidades de aprendizagem culturalmente significativas.

Para desenvolver esta perspectiva, apoiamo-nos em dados empíricos produzidos no âmbito de dois projectos de investigação em que estivemos directa e indirectamente envolvidos. Em ambos os casos recorreu-se à aplicação de várias técnicas de pesquisa, com especial destaque para a administração de inquéritos por questionário: no primeiro projecto, aos directores/gestores de departamentos de recursos humanos de várias empresas e a uma amostra de trabalhadores de cinco empresas do norte de Portugal; no segundo projecto, a uma amostra representativa de trabalhadores de uma empresa de componentes tecnológicas, da mesma região.

Terminaremos este trabalho com algumas reflexões sobre a centralidade das dimensões simbólicas nos processos de aprendizagem cultural e as potencialidades dos mecanismos de educação e da formação não-escolares na consolidação de aprendizagens culturalmente significativas, vector cada vez mais estruturante no desenvolvimento estratégico e sustentado das organizações contemporâneas.

\section{O campo da educação não-escolar: concepções, contextos e processos}

Nesta secção tentaremos sintetizar algumas das propostas teóricas que marcaram o percurso inicial de (re)definição do universo educativo, designadamente as que procuraram clarificar o sentido da problemática da educação não-formal e sobretudo aquelas que, a partir de um determinado momento (década de sessenta em diante), fizeram a apologia da educação numa perspectiva holística (ou integrated educacional approach, de acordo com La Belle e Verhine, 1975) e enquadrada na filosofia da educação permanente (Brembeck, 1976; La Belle, 1982). Desde então as noções de educação formal, educação não-formal e educação informal naturalizaram-se no seio do discurso educacional (Trilla Bernet, 1998), muito embora a tal não tivesse correspondido uma reformulação dos significados e do estatuto de cada uma delas no interior do campo educativo. Apesar do cenário de "crise" diagnosticado no projecto universal de escolarização (Coombs, 1968, 
1985), a forma escolar continuou, todavia, a exercer a sua hegemonia no processo global da educação, não obstante os imperativos de natureza socioeconómica inerentes ao modelo de desenvolvimento preconizado terem impulsionado a procura de alternativas educacionais mais flexíveis, menos onerosas e mais eficazes do ponto de vista da satisfação das necessidades imediatas dos indivíduos e das comunidades.

Contributos para a clarificação das noções de educação não-formal e de educação informal têm surgido amiúde nos últimos quarenta anos, muito embora as propostas de Coombs e Ahmed (1975) tenham exercido a sua hegemonia nos discursos e agendas de investigação dos campos da educação e formação. No caso específico da educação não-formal, acentuou-se desde então a preocupação de clarificar o seu lugar, as funções e o seu papel no quadro mais vasto do campo educativo, como complemento, suplemento ou alternativa sobretudo em relação à educação formal (Paulston, 1972). Quer em Coombs e Ahmed (1975) quer em Paulston (1972) observou-se o estabelecimento de fronteiras analíticas entre os distintos modos educacionais, desde um pólo mais estruturado, rígido, sistemático e hierarquizado (educação formal), até ao outro pólo do continuum, mais flexível, disperso, difuso, fragmentado e fluído (educação informal). Sendo certo que nem sempre é possível estabelecer com clareza as fronteiras entre os vários modos educacionais (sobretudo entre o formal e o não-formal), a multiplicidade de programas, contextos e processos potencialmente catalogáveis nesse esboço de análise faz emergir situações híbridas e distintas combinações entre eles. Apesar deste reparo, as características modais da educação não-formal e da educação formal tendem a separá-las, sobretudo no que concerne à estruturação dos espaços-tempo de aprendizagem, aos objectivos, à definição dos actores educativos, à relação que estes estabelecem com o conhecimento, entre outras variáveis significativas.

Para além da recensão dos distintos modos educacionais, interessa-nos compreender de que modo estes se expressam no quadro das várias instituições educativas e formativas, acentuando-se o papel do contexto na produção dos sentidos da aprendizagem (La Belle, 1982; Trilla Bernet, 1998; Rogers, 2004). Do ponto de vista analítico torna-se relevante observar o grau de contextualização da formação e das aprendizagens e as possibilidades de participação que os actores têm na definição das suas dinâmicas, dos seus objectivos e dos seus usos (Rogers, 2004). Suponhamos uma determinada situação escolar, no contexto da sala de aula, onde se confrontam simultaneamente o currículo oficial, o estatuto formal do professor e as disposições normativas-legais, por um lado, e o modo como são geridas as interacções entre professor e alunos, o modo como está organizado o espaço, 
o modo como se processa a aprendizagem, por outro lado. Inserindo-se a escola num modo predominantemente formal, torna-se evidente que as suas actividades recobrem uma série de características que ultrapassam largamente o cânone burocrático-formal do currículo, sendo previsível a construção de um percurso paralelo de aprendizagens proporcionadas por vivências e experiências de tipo não-formal e informal ocorridas no quotidiano da organização escolar.

A mesma proposta analítica serve igualmente para observarmos os mais variados processos e práticas de educação e formação em contexto empresarial. E assim, sendo a empresa uma instituição de carácter formal, tende a propiciar aos seus actores uma multiplicidade de experiências de aprendizagem que tanto pode ancorar na prática quotidiana do trabalho, portanto de um modo informal, como pode resultar da adesão e/ou imposição a programas de formação visando, sobretudo, a melhoria do processo produtivo. Neste caso, o dia-a-dia da empresa é fértil em solicitações educativas de cariz não-formal, interna ou externamente promovidas. $\mathrm{Na}$ medida em que estas são frequentemente certificadas e certificadoras, obedecem a uma estrutura organizativa dos espaços e tempos pedagógicos, os processos de formação decorrem de forma sistemática e são, normalmente, direccionados a grupos específicos da organização de trabalho. Não raramente as lógicas formativas características deste modo educativo tendem a ignorar as especificidades da estrutura e da acção organizacional, impondo-se como um requisito de mudança e como uma resposta adequada às supostas necessidades de qualificação dos diversos trabalhadores. No entanto, e dadas as proximidades deste modo de educação com a "forma" e os conteúdos escolares, não estranha que se desenvolvam comportamentos de desconfiança e de resistência por parte de alguns sectores da organização quando se perspectivam tempos de formação, nomeadamente entre aqueles cuja experiência escolar se revelou menos profícua. Nestas situações, tende a ocorrer um desenraizamento do trabalhador do seu contexto de trabalho, que obnubila as possibilidades formativas de um modo educativo informal, assente na experienciação diária das relações de trabalho e nas dinâmicas próprias das interacções socioprofissionais e que, na maior parte das vezes, consubstancia aprendizagens culturalmente significativas.

\section{A problemática da cultura organizacional: perspectivas e processos de construção do simbólico}

A problemática da cultura organizacional aparece frequentemente associada às ideias de gerencialismo e de tecnocracia, em contradição com as ideias de democracia e de participação. Tal como acontece com outros 
objectos de investigação social, as imagens que se sedimentam no tempo apenas correspondem a uma das múltiplas facetas da realidade investigada, normalmente aquela que melhor se concilia, se articula e reforça os valores e as ideologias dominantes. O caso da cultura organizacional é, a este propósito, elucidativo: se, por um lado, as perspectivas de natureza mais gestionária defendem que as culturas integradoras favorecem a construção da excelência e o alcance da competitividade organizacional, por outro lado as perspectivas críticas e reflexivas investem no estudo dos processos de construção e manifestação do cultural, relativizando o seu uso como técnica ao serviço da produtividade. No primeiro caso, a cultura apresenta-se como uma técnica, um instrumento eficaz de gestão de recursos humanos; no segundo caso, a cultura destaca-se como um pertinente campo de estudo do comportamento humano.

Sabendo de antemão que a primeira faceta desta problemática granjeou internacionalmente uma considerável popularidade, traduzida pelo sucesso editorial de algumas obras de referência, como as de E. Schein (1985), W. Ouchi (1986), T. Peters e R. Waterman (1987), T. Deal e A. Kennedy (1988), entendemos, no entanto, que a outra faceta, de natureza mais crítica e reflexiva, nos oferece um leque de possibilidades interpretativas e compreensivas para a abordagem que desenvolvemos neste trabalho.

Compreender o modo como nasce, se desenvolve e consolida a cultura no seio das organizações constitui, sem dúvida, uma das vertentes mais relevantes no âmbito dos estudos críticos. Mobilizando como fonte de inspiração os vários enfoques teóricos - cultura como variável independente, cultura como variável dependente e cultura como metáfora (Torres, 1997, 2004) - que enfatizam distintos factores no processo de construção da cultura das organizações, o nosso posicionamento assenta fundamentalmente em três pressupostos. Primeiro, a cultura traduz-se num processo dinâmico em permanente reconstrução por via da interacção dos actores sociais; segundo, tal processo desenvolve-se na longa duração, em espaços-tempos colectivamente partilhados pelos actores, apresentando regularidades, mas igualmente descontinuidades culturais; terceiro, o processo ou o modo como a cultura se desenvolve só pode ser apreendido a partir da consideração de uma multiplicidade de factores internos e externos às organizações, como por exemplo factores de natureza social, comunitária, política, religiosa, organizacional, entre outros. Neste sentido, a cultura das organizações desenvolve-se e sedimenta-se no tempo, através das metamorfoses quotidianas operadas pelos actores em relação a um conjunto de condicionamentos internos e externos aos seus contextos organizacionais. Destas reacções (colectivas ou sectoriais) aos constrangimentos estruturais 
nascem e instalam-se progressivamente os costumes, os hábitos, as rotinas, os rituais, enraizando-se e difundindo-se ao todo organizacional. Apesar de aparentemente invisíveis ao olhar do gestor, este tipo de camadas sedimentares transforma-se, na long durée, em regularidades culturais, naquilo a que se convencionou designar de ethos organizacional, uma espécie de matriz simbólica expressa pelos padrões comportamentais que sustentam o funcionamento quotidiano das organizações.

Numa segunda instância, interessa desmistificar um certo pensamento monocultural dominante entre as perspectivas gestionárias, que apenas considera como cultura aquilo que é efectivamente partilhado pelos actores. Ou seja, a cultura, neste sentido meramente integrador, representaria, tão-somente, os padrões simbólicos efectivamente partilhados e aceites pelos actores. Em contraposição, de acordo com as correntes mais críticas, a partilha dos elementos culturais (valores, crenças, opiniões,...) pelos diferentes actores, só pode ser abordada como se de uma questão de grau se tratasse, situando-se, portanto, ao longo de um intermitente continuum revelador de distintos graus de coesão cultural entre os actores. Assim, e procurando explicitar a seguinte representação gráfica (figura 1), é possível encontrar no seio das organizações pelo menos três tipos de cultura, consoante o grau e a especificidade das suas manifestações: a cultura integradora, quando o grau de partilha e de identificação colectiva com os objectivos e valores da organização é elevado; a cultura diferenciadora, quando o grau de partilha cultural apenas se restringe ao grupo de referência, sendo provável a coexistência de distintas subculturas no mesmo contexto organizacional; por fim, a cultura fragmentadora, quando se constata o grau mínimo de partilha cultural, frequentemente adstrita à mera esfera individual (Meyerson e Martin, 1987; Martin e Meyerson, 1988; Frost et al., 1991; Martin, 1992, 2002).

FIGURA 1 - Manifestações da cultura organizacional: cultura integradora, diferenciadora e fragmentadora

(-) Cultura fragmentadora

(-) Nenhuma partilha Nível: individual

\section{Cultura diferenciadora}

Alguma partilha Nível: subgrupos
Cultura integradora (+)

Máxima partilha (+) Nível: organização

Nesta óptica, a questão nuclear não será a de saber se a organização tem ou não uma cultura, estritamente no sentido integrador do termo, mas, sobretudo, a de conseguir identificar diferentes manifestações culturais num determinado contexto organizacional, compreender os múltiplos processos 
que presidem à sua construção e o seu real impacto ao nível do desenvolvimento estratégico, designadamente ao nível das políticas e das práticas de formação efectivamente actualizadas.

Enquanto de um ponto de vista meramente gestionário se privilegia o diagnóstico da cultura dominante e se investe na sua gestão e/ou mudança com vista à produção de competitividade, excelência e eficácia (vejam-se, por exemplo os trabalhos de Ouchi, 1986; Peters e Waterman, 1987; Deal e Kennedy, 1988; Hofstede et al., 1990), do ponto de vista mais crítico e reflexivo procura-se apreender as diferentes configurações culturais coexistentes nas organizações, de modo a compreender os seus trajectos de desenvolvimento e as suas manifestações dominantes (Alvesson, 2002; Alvesson e Berg, 1992; Martin, 2002). Na primeira modalidade, a mais praticada no campo da gestão de recursos humanos, tende-se a simplificar excessivamente a realidade cultural da organização, reduzindo-a à hegemonia de uma configuração dominante, frequentemente virtual, porque colocada no plano do desejável, em função da qual se desenvolvem modalidades de formação de tipo monocultural. A construção de dispositivos de formação, nas suas diversas acepções (reciclagem, actualização, complemento, treino, reconversão, etc.), obedece quase sempre a uma lógica de tipo instrutiva, tecnicista, mecânica, que reforça e reproduz o modelo formal de aprendizagem escolar. $\mathrm{Na}$ segunda modalidade, a menos conhecida e, por conseguinte, a menos adoptada no campo da gestão, propõe-se um olhar centrado nas especificidades culturais e a sua articulação com as dimensões políticas e estratégicas da organização, com particular destaque para as políticas de formação, agora concebidas de uma forma multirreferenciada. Privilegia-se, por conseguinte, uma formação na e a partir da(s) cultura(s) e não tanto uma cultura da formação (Torres, 2001), uma espécie de ideologia tecnocrática, exclusivamente refém de determinações de índole economicista e produtivista.

\section{A cultura imaginada e a formação como estratégia de uma aparente modernidade}

Uma das conclusões mais substantivas apresentadas pelo projecto de investigação Trappo ${ }^{1}$, vem justamente sustentar a ideia de centralidade confe-

\footnotetext{
${ }^{1}$ O projecto de investigação Políticas e Práticas de Formação em Contextos Organizacionais - Projecto Trappo (Training Policies and Practices in Organisations) - desenvolveu-se no âmbito do Programa Leonardo Da Vinci, financiado pela Comissão Europeia. Neste projecto participaram três equipas de investigação: uma equipa promotora constituída pelo coordenador Carlos Estevão, por dois docentes/investigadores do Departamento de Sociologia da Educação e Administração Educacional do Instituto de Educação e Psicologia da Universidade do Minho e três investigadores da TecMinho - Associação Universidade Empresa para o Desenvolvimento (Guimarães); e duas
} 
rida à cultura e à formação no quotidiano da gestão das empresas. Efectivamente, foi notório nos testemunhos dos gestores/directores dos departamentos de recursos humanos de 78 empresas do norte do país que a cultura e a formação se encontram entre as principais prioridades estratégicas das empresas. No entanto, se parece claro que no plano discursivo houve uma significativa incorporação da agenda da modernidade, bem expressa pela forma como os gestores se pronunciaram acerca das potencialidades emancipatórias da formação e da cultura no local de trabalho, do ponto de vista das políticas e das práticas efectivamente operacionalizadas constatou-se um défice de concretização, indicativo de que a realidade organizacional portuguesa contradiz claramente o plano das intenções. Por exemplo, tanto ao nível dos resultados dos inquéritos por questionário, como ao nível das entrevistas semi-estruturadas realizadas aos referidos gestores, foi possível confirmar a crença numa imagem de cultura organizacional de natureza integradora e na relevância que os processos de formação desempenhavam no seu reforço. No entanto, quando se procurou indagar os fundamentos para tais convicções, surgiram argumentos de ordem intuitiva, experiencial e emotiva, nunca ancorados em conhecimentos objectivos sobre a realidade onde se exerce a actividade profissional. A cultura não passava, portanto, de uma impressão que se percepcionava espontaneamente e a formação um mero mecanismo técnico que traduzia a (pretensa) adesão da empresa à modernidade e ao progresso.

Entretanto, os cinco estudos de caso desenvolvidos no âmbito do mesmo projecto, entre 1998 e 2001, revelaram também o mesmo tipo de abordagens formativas desenvolvidas naqueles contextos e a sua (des)articulação com a cultura da organização. Resumidamente, a organização do processo formativo obedecia à seguinte sequência: 1) diagnóstico de necessidades restrito a informações dadas pelo chefe de secção/serviço, sem consulta aos potenciais formandos; 2 ) proposta elaborada unilateralmente pela empresa; 3) mecanismos de difusão da formação de tipo informal e casual; 4) ausência de iniciativas individuais para a frequência de formações; 5) formação centrada nas competências específicas; 6) metodologias pedagógicas de tipo formal e expositivo.

equipas parceiras convidadas, uma da Universidade de Jonkoping (Suécia), coordenada por Benny Hjern, e outra da Université Pierre Mendés France, de Grenoble (França), coordenada por G. Figari. No contexto da temática genérica Políticas e Práticas de Formação, a equipa do projecto elegeu para estudo mais aprofundado 4 linhas de investigação: 1) Cultura e Identidades Organizacionais; 2) Cidadania Organizacional; 3) Redes Organizacionais e Profissionais; 4) Pilotagem das Políticas de Formação (Estêvão, 2002, 2006). 


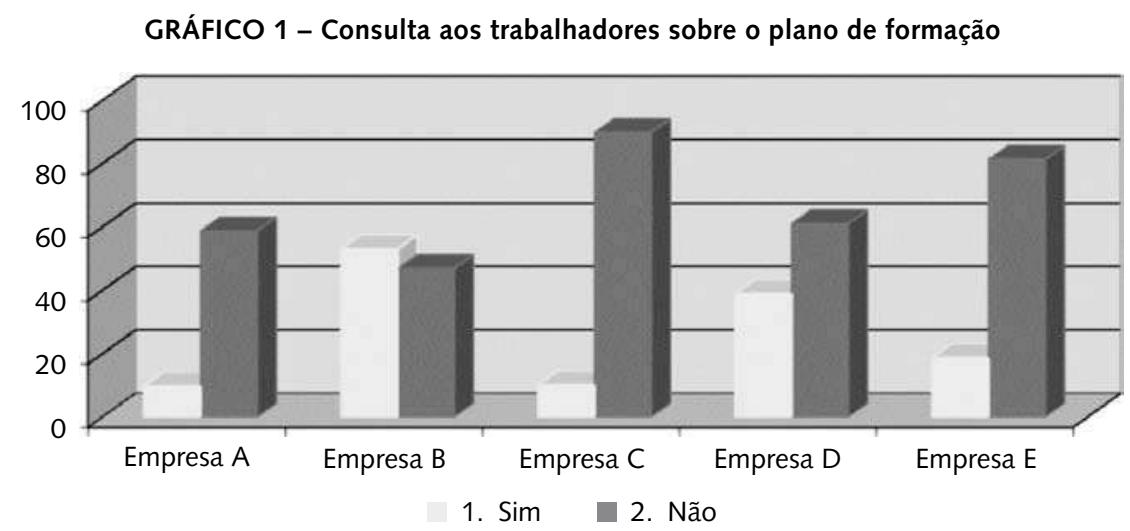

Fonte: Inquérito do projecto Trappo. Cf. Estêvão (2002, 2006).

De entre as empresas estudadas, a grande maioria dos trabalhadores afirmou não ter sido consultada sobre o plano de formação, com a excepção da empresa $\mathrm{B}$, o que vem denunciar que os mesmos se encontravam arredados, como sujeitos activos, do processo de definição do modelo de formação (gráfico 1). Tratava-se, portanto, de uma formação externamente concebida em função de prioridades técnicas e de estratégias políticas que excluem os actores dos processos inerentes à sua construção. Senão vejamos: a forma como a maioria dos trabalhadores era informada acerca dos planos de formação reflectia, uma vez mais, o carácter externo e distante conferido à formação, já que se privilegiava o elo hierárquico como mecanismo de difusão da informação - a informação oral dada pelo responsável de serviço foi o meio predominante em quatro empresas para dar a conhecer a existência de formação, meio que difere apenas na empresa $\mathrm{B}$, em que foi mais frequente fazer circular a informação através de um documento formal (quadro 1).

QUADRO 1 - Conhecimento da existência de formação por parte dos trabalhadores (\%) (*)

\begin{tabular}{|l|c|c|c|c|c|}
\hline \multicolumn{1}{|c|}{ Meios } & Empresa A & Empresa B & Empresa C & Empresa D & Empresa E \\
\hline $\begin{array}{l}\text { 1. Por um documento distribuído } \\
\text { na empresa }\end{array}$ & 30,4 & $\mathbf{6 7 , 6}$ & 15,1 & 13,8 & 44,3 \\
\hline $\begin{array}{l}\text { 2. Por informação oral dada por } \\
\text { um responsável }\end{array}$ & $\mathbf{3 8 , 2}$ & 35,3 & $\mathbf{8 6 , 6}$ & $\mathbf{4 4 , 6}$ & $\mathbf{5 8 , 0}$ \\
\hline $\begin{array}{l}\text { 3. Por conversas informais com } \\
\text { outros colegas }\end{array}$ & 11,8 & - & 1,7 & 9,2 & 4,6 \\
\hline 4. Por outro meio & - & - & - & - & - \\
\hline
\end{tabular}

Fonte: Inquérito do projecto Trappo. Cf. Estêvão (2002, 2006).

$\left({ }^{*}\right)$ Questão de resposta múltipla. As percentagens correspondem às escolhas que cada categoria obteve autonomamente, não se podendo por isso somar os quatro meios indicados no quadro. 
A exteriorização do processo de formação em relação aos actores e às suas especificidades culturais verificou-se igualmente ao nível do carácter não voluntário das inscrições, já que se constatou que a esmagadora maioria dos trabalhadores referiu que a origem da inscrição na última acção de formação frequentada obedeceu a uma proposta da empresa e não a um pedido ou iniciativa individual (gráfico 2). A forma como se pensava, organizava e implementava a formação nestas empresas não se sustentava nas especificidades culturais da organização, nem tão pouco se articulava com o tipo de cultura imaginada como dominante - a cultura integradora. Se assim fosse, os objectivos primordiais da formação centrar-se-iam, sobretudo, nas capacidades relacionais e na adaptação às mudanças e não tanto, como se depreendeu, nas competências técnicas de cada cargo/função.

\section{GRÁFICO 2 - Origem da inscrição na última acção de formação que os trabalhadores frequentaram}

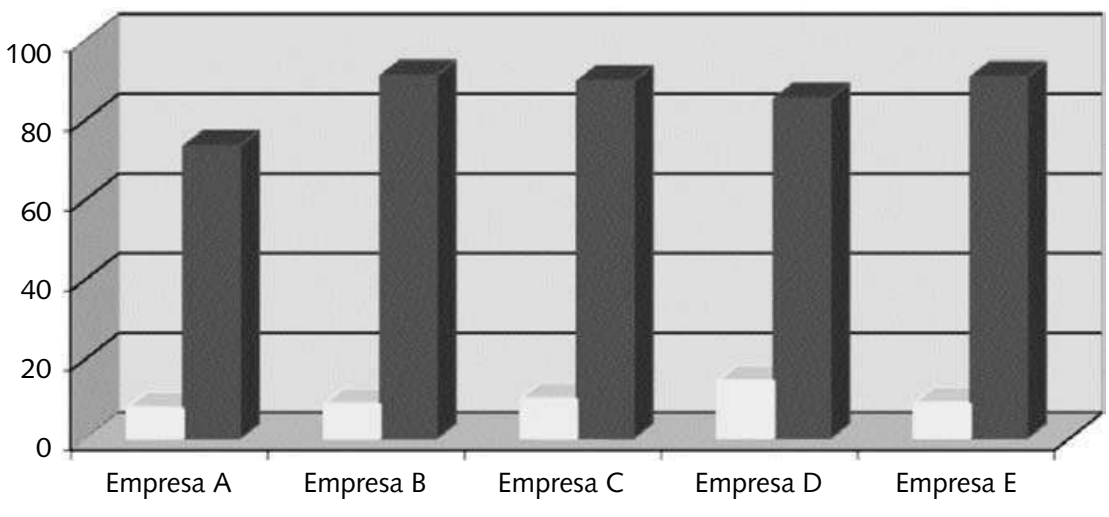

1. Pedido da minha parte

2. Proposta da empresa

Fonte: Inquérito do projecto Trappo. Cf. Estêvão (2002, 2006).

Se no tocante à organização e gestão da formação foi notória a presença de um modelo curricular externamente produzido, ao nível da sua operacionalização denotou-se o accionamento de estratégias similares ao modelo formal de ensino, privilegiando-se a sala de aula como espaço de aprendizagem e o seguimento do programa como a principal linha pedagógica norteadora. O quadro 2 é esclarecedor quanto a este dispositivo pedagógico de formação, atendendo a que o estudo de casos, de situações ou de práticas profissionais aparece em todas as empresas como a forma de animação menos adoptada, o que vem de encontro à idéia de uma formação descentrada das especificidades culturais e profissionais das organizações. 
QUADRO 2 - Formas de animação das acções de formação (\%)

\begin{tabular}{|l|c|c|c|c|c|}
\hline $\begin{array}{c}\text { Formas de animação da última } \\
\text { formação }\end{array}$ & Empresa A & Empresa B & Empresa C & Empresa D & Empresa E \\
\hline $\begin{array}{l}\text { 1. Discutir colectivamente um } \\
\text { assunto }\end{array}$ & 20,6 & 20,6 & 42,0 & 15,4 & 34,4 \\
\hline 2. Realizar trabalhos de grupo & 20,6 & 26,5 & 38,7 & 18,5 & 32,1 \\
\hline $\begin{array}{l}\text { 3. Apresentar práticas profissio- } \\
\text { nais }\end{array}$ & 11,8 & 14,7 & 42,0 & 12,3 & 31,3 \\
\hline $\begin{array}{l}\text { 4. Estudar um caso ou uma situa- } \\
\text { ção profissional }\end{array}$ & 7,8 & 11,8 & 21,8 & 7,7 & 15,3 \\
\hline $\begin{array}{l}\text { 5. Seguir o programa dado pelo } \\
\text { formador }\end{array}$ & $\mathbf{4 7 , 1}$ & $\mathbf{5 2 , 9}$ & $\mathbf{6 4 , 7}$ & $\mathbf{4 1 , 5}$ & $\mathbf{4 5 , 8}$ \\
\hline
\end{tabular}

Fonte: Inquérito do projecto Trappo. Cf. Estêvão (2002, 2006).

Se de facto a formação e a cultura ocupassem um lugar central no quadro das prioridades estratégicas das empresas, tal como verbalizaram os gestores entrevistados, teríamos encontrado outras práticas formativas mais articuladas e atentas às especificidades culturais da organização e, por conseguinte, ancoradas em pressupostos mais participativos e democráticos ao nível da concepção dos projectos, mais diversificados ao nível dos espaços-tempos de formação, mais activas e menos formais ao nível das estratégias pedagógicas; enfim, mais centradas nas múltiplas modalidades de aprendizagem cultural. Neste caso, o recurso às experiências profissionais como instrumento pedagógico assumiria particular relevo, na medida em que permitiria reconstituir os percursos de aprendizagem desenvolvidos pelos actores e (re)integrar, de forma culturalmente significativa, novos conhecimentos a partir de velhos moldes.

Em suma, é possível deduzir a hegemonia de um modelo de formação decalcado da "forma escolar" (Vincent, 1994), assente em metodologias normativas e prescritivas (uma sala, um formador, uma turma), enfatizando mais o treino individual, o carácter instrumental e adaptativo a processos de trabalho ainda demasiado estandardizados, centralizados e rigidamente estruturados. Convém realçar que a cultura imaginada pelos gestores de recursos humanos está muito longe de corresponder às culturas reais identificadas no projecto Trappo, sendo estas profundamente segmentadas e geradoras de permanentes antagonismos. $\mathrm{O}$ actual modelo de educação e de formação (de adultos) não só se encontra totalmente desarticulado com a cultura imaginada pelos gestores e/ou coordenadores da formação, como constitui uma clara ruptura com as especificidades culturais e simbólicas efectivamente sedimentadas nas organizações de trabalho. 


\section{A centralidade do não-formal e do informal na construção de aprendi- zagens culturalmente significativas}

Quando adoptamos um registo mais crítico e reflexivo na abordagem da cultura das organizações, que contemple a coexistência de distintas manifestações culturais (integradora, diferenciadora e fragmentadora), o nosso olhar recai inevitavelmente sobre os diversos processos de construção do simbólico, com particular incidência para os fenómenos de socialização e de aprendizagem cultural no local de trabalho. Trata-se de um enfoque invertido em relação ao anterior, já que deriva de um olhar "de dentro para fora", isto é, inspirado nas especificidades e nas dinâmicas culturais construídas no contexto organizacional para, a partir delas, criar e recriar modelos de gestão (nas suas vertentes técnica, social, cultural, educativa) susceptíveis de promoverem o desenvolvimento organizacional (Torres, 2001).

Neste seguimento, uma cultura tipicamente integradora - em que se verifica a partilha pelos actores de um conjunto significativo de padrões culturais, denotando-se uma forte identificação colectiva com os valores da organização, e onde se supõe um envolvimento afectivo dos actores ao seu local de trabalho - pressupõe a mobilização quotidiana de processos de socialização colectivos assentes em moldes predominantemente informais. Isto é, a integração do trabalhador processa-se por via da incorporação progressiva de um conjunto de saberes que emergem da própria experienciação social, estruturante de qualquer relação de trabalho. Esta dimensão de cariz informal, espontânea, difusa, paralela, quotidianamente desenvolvida, decorrente das interacções sociais dentro e fora do local do trabalho, traduz basicamente aquilo que se tem designado nos estudos organizacionais por aprendizagem cultural. Esta noção recobre não só o conjunto de saberes e competências técnico-funcionais inerentes ao desempenho de um cargo/função, mas, sobretudo, o conjunto de saberes tácitos e estratégicos que conferem sentido identitário à acção do trabalhador no seu contexto laboral. Muitos destes saberes reflectem diferentes modos de pensar e de agir de determinadas categorias sociais e profissionais, consubstanciando distintas formas identitárias ou, ainda, diferentes consciências de classe, recriadas no contexto de trabalho. As dimensões informais, nomeadamente as subjectividades, e os múltiplos processos de identificação dos trabalhadores, revelam-se fundamentais, como comprovou Estanque (2000) na investigação que desenvolveu numa fábrica, para a compreensão das representações e das práticas dos actores em relação ao mundo do trabalho.

O processo de aprendizagem representa simultaneamente um efeito natural do tipo de cultura dominante mas também um factor desencadeador de novas configurações culturais, constituindo portanto, uma categoria 
relevante do ponto de vista da gestão das organizações. Se, de facto, se elege como objectivo estratégico da organização, o reforço dos traços já evidentes da cultura integradora, o modelo de formação mais congruente com tal propósito teria de se inspirar nos mecanismos já consolidados de aprendizagem cultural, de modo a reforçar o mundo simbólico já construído pelos trabalhadores, ensaiando modalidades formativas integradas na própria estratégia de socialização (Lesne e Minvielle, 1988: 28). Só através da reconstituição ("organizada e intencional") do processo de socialização ("natural e selvagem") e dos mecanismos de aprendizagem no local de trabalho seria possível garantir a reconstrução significativa de novos conhecimentos, suportados em estratégias adequadas e não disruptivas com o "mundo vivido" do actor. E, neste seguimento, partilhamos a visão de Mehaut (1990), quando afirma ser necessário proceder à recomposição do tempo de trabalho, inscrevendo o processo de formação no lugar do tempo de trabalho ou, dito de outro modo, reintegrando a formação nos diversos contextos laborais.

QUADRO 3 - Manifestações da cultura, aprendizagem cultural e concepções de formação

\begin{tabular}{|l|l|l|l|}
\hline $\begin{array}{c}\text { Manifestações da } \\
\text { cultura organizacional }\end{array}$ & \multicolumn{1}{|c|}{$\begin{array}{c}\text { Tipo predominante } \\
\text { de aprendizagem }\end{array}$} & $\begin{array}{c}\text { Concepção predo- } \\
\text { minante de formação }\end{array}$ & $\begin{array}{l}\text { Formalização predo- } \\
\text { minante de formação }\end{array}$ \\
\hline Cultura integradora & $\begin{array}{l}\text { Informal/contexto de } \\
\text { trabalho }\end{array}$ & $\begin{array}{l}\text { Formação/socializa- } \\
\text { ção no local de tra- } \\
\text { balho }\end{array}$ & $\begin{array}{l}\text { Projecto de forma- } \\
\text { ção/empresa }\end{array}$ \\
\hline Cultura diferenciadora & Multirreferenciada & $\begin{array}{l}\text { Micropolíticas de for- } \\
\text { mação }\end{array}$ & $\begin{array}{l}\text { Subprojectos de } \\
\text { formação }\end{array}$ \\
\hline Cultura fragmentadora & $\begin{array}{l}\text { Formal/exterior ao con- } \\
\text { texto de trabalho }\end{array}$ & $\begin{array}{l}\text { Formação descontí- } \\
\text { nua e intermitente }\end{array}$ & $\begin{array}{l}\text { Planos casuais de } \\
\text { formação }\end{array}$ \\
\hline
\end{tabular}

Face a uma cultura organizacional tipicamente diferenciadora - caracterizada pelo dissenso quanto aos valores, crenças e ideologias e traduzida pela coexistência de subculturas fortes e concorrenciais - o mais provável é encontrar no mesmo espaço organizacional diferentes modalidades de socialização e de aprendizagem consoante as especificidades das subculturas em presença. A heterogeneidade social, económica, técnica e cultural entre os diversos loci de cultura coexistentes, desencadeia naturalmente distintas trajectórias de integração e de segmentação dos trabalhadores, contribuindo para a criação e sedimentação de aprendizagens referenciadas a uma grande diversidade de estratégias: formais e informais, individuais e colectivas, sequenciais e não sequenciais, programadas e não programadas. 
Neste quadro cultural multifacetado, a política de formação da organização teria de se articular, uma vez mais, com as singularidades das várias subculturas, de forma a se conseguir reinventar modelos formativos, que, independentemente dos seus objectivos específicos, terão de representar, na perspectiva dos seus públicos-alvo, um autêntico espaço-tempo de aprendizagem significativa. Para estes casos, assim como para quase todos, arriscamos afirmar que as "receitas" pedagógicas para o sucesso da formação se encontram não em catálogos ou menus, por muito progressistas que possam parecer, mas justamente na capacidade de o gestor/coordenador de recursos humanos saber verter o conhecimento e as aprendizagens subjectivadas pelos actores em renovados moldes sustentadores de novas aprendizagens.

Por fim, perante a presença de uma cultura de tipo fragmentador - caracterizada pela desconexão cultural, pela diluição total do sentido de pertença, pela fragmentação da partilha e pela individualização das trajectórias profissionais - onde as aprendizagens se tornam cada vez mais formais, individualizadas e descontínuas, faz sentido repensar na função estratégica da formação, ora como mecanismo de reforço da fragmentação, ora como veículo propiciador de uma certa desfragmentação, conducente à recuperação do sentido de identidade, ainda que, numa primeira fase, fluida e frágil. Em ambos os casos, construir uma política de formação propiciadora de aprendizagens significativas representa um difícil mas pertinente desafio, apenas possível se atendermos, novamente, às especificidades culturais dos trabalhadores. Isto é, dada a natureza das aprendizagens culturais já desencadeadas, sobretudo de cariz individual, formal e descontínuo, interessa estruturar modelos formativos que tanto obedeçam a esta lógica (quando o objectivo é o reforço da cultura fragmentadora), como a neguem e a confrontem (quando o objectivo é o de superar a fragmentação), pela adopção de estratégias promotoras do consenso, da partilha, do envolvimento, da identificação com o grupo ou com a organização.

Estes três cenários representam teoricamente três tipos de manifestações culturais presentes, com diferentes graus de expressão, nas organizações de trabalho. Em todos eles é possível depreender um certo tipo de socialização e de aprendizagem cultural dominante. Deste exercício de reflexão, apoiado em alguns dados de investigação empírica, foi possível construir uma correlação de sentido entre as duas problemáticas em análise - cultura organizacional e processos de socialização e de aprendizagem. À medida que avançámos na exploração desta proposta analítica, a relação entre o grau de formalização das aprendizagens e o tipo correlativo de cultura dominante foi-se assumindo cada vez mais como uma possibilidade heurística na compreensão dos fenómenos organizacionais. 
Efectivamente, quanto maior o grau de partilha cultural, mais informal tende a ser a socialização e, consequentemente, mais fluida e flexível a aprendizagem no local de trabalho. Os espaços-tempo marcados por elevados graus de informalidade tendem a promover a subjectivação do conhecimento, proporcionando aprendizagens ancoradas em valores e em normas vivenciadas em grupo ou colectivamente. Em sentido contrário, à medida que os processos de aprendizagem se vão formalizando e tornando mais rígidos e distantes, os padrões culturais tendem a diferenciar-se e, no limite, a diluir-se, fragmentando-se.

\section{FIGURA 2 - Manifestações da cultura organizacional e modalidades de aprendizagem}
(-) Cultura fragmentadora
Cultura diferenciadora
Cultura integradora (+)

(-) Nenhuma partilha Aprendizagem formal/ individual
Alguma partilha Aprendizagem não-formal/ subgrupo
Máxima partilha (+)

Aprendizagem informal/ colectiva

Neste sentido, independentemente da sua importância, do lugar que ele ocupa nas prioridades estratégicas e políticas da organização e da forma como se procede à sua implementação, o processo formativo deveria ancorar sempre nas especificidades culturais da organização. Se isto parece inequívoco, não faz sentido menosprezar a articulação entre os processos formativos e os projectos de aprendizagem protagonizados pelos diferentes trabalhadores nos seus locais de trabalho. Exemplificando, as formas de aprendizagem social e cultural experienciadas quotidianamente pelos actores nos seus contextos profissionais representam o seu "mundo vivido do trabalho" (Dubar, 1997a: 50), em torno do qual outras aprendizagens terão de ser induzidas. Isto é, mais do que identificar saberes experienciais, o trabalho de formação “(...) procura induzir situações em que os indivíduos se reconheçam nos seus saberes e sejam capazes de incorporar no seu património experiencial os próprios saberes produzidos pelas experiências de formação" (Correia, 1997: 37). O desenvolvimento de modelos de formação externamente concebidos e, portanto, divorciados dos contextos reais de trabalho, tende a esvaziar de significado todo o acto formativo, porque institui a separação entre o saber e a acção.

Recorrendo aos dados de um outro projecto de investigação dirigido por Lima (2004), ${ }^{2}$ onde se administrou um inquérito por questionário aos tra-

${ }^{2}$ O projecto de investigação foi dirigido por Licínio C. Lima, entre 2001 e 2004, no âmbito da Unidade de Educação de Adultos da Universidade do Minho (Lima, 2004). 
balhadores de uma empresa do norte do país, constatou-se uma realidade peculiar nos modos dominantes de aprendizagem (quadro 4): em primeiro lugar, os trabalhadores afirmaram maioritariamente que aprenderam o essencial relativo ao seu posto de trabalho "porque outros colegas me ensinaram" $(93,3 \%)$ e "a fazer fazendo, pela prática" $(83,4 \%)$; em segundo lugar, rejeitaram liminarmente terem aprendido o que sabem "porque frequent[aram] cursos de formação fora da fábrica" (86\%), "porque já tinha experiência profissional semelhante noutras fábricas" $(85,2 \%)$ e "porque frequent[aram] cursos de formação profissional fora da escola" $(83,3 \%)$. Por um lado, sobressaiu a valorização, por parte da maioria dos trabalhadores, dos processos colectivos, informais e experienciais de aprendizagem, revelador da importância destes mecanismos para a aquisição de conhecimentos; por outro lado, destacou-se com alguma expressividade a rejeição dos contextos de formação profissional como momentos relevantes de aprendizagem. Face a este cenário, fará sentido insistir no desenvolvimento de projectos de formação profundamente escolarizados e reprodutivos das lógicas de ensino-aprendizagem formais, justamente aquelas que mais contradizem as formas pelas quais estes actores aprenderam a aprender?

QUADRO 4 - "Como é que aprendeu a fazer aquilo que faz no seu posto de trabalho?"

\begin{tabular}{|c|c|c|c|c|}
\hline & \multicolumn{2}{|c|}{ SIM } & \multicolumn{2}{|c|}{ NÃO } \\
\hline & $\%$ & $\mathrm{n}$ & $\%$ & n \\
\hline Aprendi a fazer fazendo, pela prática $(n=229)$ & 83,4 & 191 & 16,6 & 38 \\
\hline Aprendi porque outros colegas me ensinaram $(n=240)$ & 93,3 & 224 & 6,7 & 16 \\
\hline $\begin{array}{l}\text { Aprendi porque frequentei cursos de formação profissional fora } \\
\text { da escola }(n=215)\end{array}$ & 16,7 & 36 & 83,3 & 179 \\
\hline Aprendi na escola $(n=213)$ & 25,4 & 54 & 74,6 & 159 \\
\hline $\begin{array}{l}\text { Já tinha experiência profissional semelhante noutras fábricas } \\
(n=216)\end{array}$ & 14,8 & 32 & 85,2 & 184 \\
\hline $\begin{array}{l}\text { Aprendi porque frequentei cursos de formação nesta fábrica } \\
(n=215)\end{array}$ & 42,3 & 91 & 57,7 & 124 \\
\hline $\begin{array}{l}\text { Aprendi porque frequentei cursos de formação fora desta fábrica } \\
(\mathrm{n}=215)\end{array}$ & 14,0 & 30 & 86,0 & 185 \\
\hline O meu chefe ajudou-me $(n=217)$ & 62,8 & 162 & 21,3 & 55 \\
\hline Outra $(n=23)$ & 47,8 & 11 & 52,2 & 12 \\
\hline
\end{tabular}

Fonte: Inquérito do Relatório final do projecto "A Fábrica" (Lima, 2004). 


\section{Olhando a aprendizagem cultural como opção estratégica de educação/ formação}

Ao longo deste artigo temos vindo a argumentar a necessidade de articular o mundo da cultura das organizações com o mundo da formação e educação (profissional) de adultos, procurando demonstrar a sua pertinência para o desenvolvimento estratégico da organização. Independentemente dos vários cenários de articulação acima enunciados (cultura $\leftrightarrow \rightarrow$ aprendizagem $\leftrightarrow \rightarrow$ formação), o tópico aprendizagem cultural mereceu um enfoque privilegiado por nos parecer, desde o início, um factor relevante na construção da cultura e, paralelamente, um mecanismo central na regulação dos processos de formação. Perspectivada como uma dimensão constitutiva do processo global de socialização, a aprendizagem cultural no local de trabalho proporciona, de facto, uma compreensão mais operatória quer dos diversos factores intervenientes nos processos de construção do conhecimento, quer dos distintos processos de subjectivação do trabalho. Por isso, na óptica da gestão de recursos humanos, em geral, e da perspectiva da gestão da formação, em particular, o conhecimento aprofundado desta realidade representa também uma importante estratégia de autoformação.

$\mathrm{Na}$ esteira de alguns autores de origem francófona, tais como Lesne e Minvielle, (1988), Malglaive (1988), Dubar (1997b, 2006), defendemos uma ruptura com a hegemonia de um modelo de formação assente exclusivamente em moldes formais, escolares e burocráticos e, em alternativa, sugerimos a construção participativa de múltiplas configurações formativas em articulação com as especificidades culturais dos contextos de trabalho. Admitindo a existência de uma forte correlação entre as formas de educação e formação não-escolar (informal e não-formal) e o reforço das identidades culturais, com claras implicações ao nível do desenvolvimento de aprendizagens significativas e duráveis, reiteramos as ideias de Lesne e Minvielle (1988: 29), escritas nos finais da década de oitenta, a propósito da concepção da "formação como uma reconstrução do processo de socialização". Efectivamente, as formas de intervenção pedagógica de cariz eminentemente não-formal e informal mobilizam saberes experienciais dos actores-sujeitos, recorrendo para o efeito a uma espécie de reelaboração dos seus processos de socialização em função do tipo de aprendizagens visadas.

Assim, este aparente isomorfismo entre processo de socialização natural existente nos universos sociais de pertença e processo de formação não representa uma simples repetição cumulativa, mas sim uma recomposição-reconstrução dos saberes, isto é, um "remodelação finalizada" de processos existentes, através da adaptação do tempo de formação à cronologia dos tempos sociais: “(...) verifica-se que a actividade de formação 
adapta-se à cronologia dos tempos sociais dos indivíduos e dos grupos" (Lesne e Minvielle, 1988: 29). É nesta linha de pensamento que surgem novas concepções de formação mais preocupadas em restabelecer, no contexto de trabalho, uma mais expressiva democratização das "competências" socialmente construídas (Castagnos e Mouy, 1990) pelo recurso à premissa pedagógica formação na e pela acção. Por exemplo, a animação de equipas de trabalho (Wittorski, 1997), a realização colectiva de tarefas comuns (Specogna, 2002), o teatro de empresa (Verzat, 2002), a gestão de conflitos (Dubar, 2006), os workshops, as visitas de estudo, constituem estratégias pedagógicas possíveis e ensaiadas em território francês. As experiências quotidianas dos actores-sujeitos, ao suporem uma relação emocional com imagens simbólicas e ao implicarem a subjectividade na incorporação de saberes, tornam a aprendizagem no local de trabalho eminentemente cultural. Trata-se, então, de uma aprendizagem baseada na interiorização de saberes, em primeiro lugar “(...) saberes da acção experimentados numa prática significante, isto é, ligados a um compromisso pessoal" (Dubar, 2006: 158). No campo específico do trabalho e do emprego, estas aprendizagens configuram frequentemente formas identitárias ou identidades profissionais profundamente enraizadas nos modos de estar, fazer e sentir a relação de trabalho. É, também, no local de trabalho que se constrói a individualidade e identidade pessoal através da resolução diária de problemas que implicam um cada vez maior envolvimento do trabalhador. Por tudo isto, o conhecimento aprofundado dos processos de construção das aprendizagens culturais constitui, em nosso entender, um eixo central na (re)construção de políticas de formação, sobretudo quando se pretende que elas revertam em efectivos momentos de aprendizagem significativa.

Olhando para as recentes transformações do trabalho e do emprego nos últimos anos em Portugal, verificamos uma crescente complexificação das trajectórias profissionais, cada vez mais ancoradas em múltiplos empregos, na acumulação de saberes e competências diversas, na experienciação de distintos ambientes de trabalho, associados a diferentes estruturas organizacionais. Este quadro de progressivas mutações arrasta consigo a necessidade de romper com uma visão escolarizada da formação, essencialmente associada ao somatório de momentos formais não articulados de ensino - com os riscos inerentes de uma rápida obsolescência da informação face à rápida evolução dos conhecimentos -, e de instituir um outro paradigma assente na centralidade do percurso de formação do profissional (Canário et al., 2002: 16), encarando-o como um sujeito da sua própria formação ou, nas palavras de Dubar (2006: 154), “um sujeito em aprendizagem”. 
Esta visão da formação enquanto processo contínuo de construção de aprendizagens culturalmente significativas, ganha ainda mais sentido no quadro das mudanças aceleradas dos modelos organizacionais de trabalho: a tendência para substituir a lógica fordista de produção pela lógica de trabalho em rede constitui, hoje, um sério desafio para o campo da gestão da formação contínua de adultos. Efectivamente, o trabalho em rede, ao romper com a segmentação e atomização do trabalho e com uma forte cultura de dependência e de execução restrita de tarefas, passa a exigir, em contrapartida, o trabalho em equipa, a polivalência de funções, a construção de culturas de interacção e de resolução de problemas. Nestes casos, a formação centrada nas carências ligadas ao posto de trabalho, nas competências específicas e na capacitação individual perde claramente sentido, para dar lugar a uma outra modalidade formativa capaz de apelar a capacidades de natureza analítico-simbólica para a resolução de problemas imprevisíveis, de mobilizar as dimensões colectivas do exercício de trabalho e de identificar as equipas de trabalho em exercício no contexto da organização. A multiplicação de conhecimentos sobre as próprias dinâmicas de funcionamento das organizações, nomeadamente ao nível das aprendizagens culturais, induzirá, estamos em crer, “(...) novas dinâmicas e dispositivos de formação no contexto de trabalho, através da implicação e mobilização das capacidades cognitivas e afectivas do pessoal" (Canário et al., 2002: 18) e proporcionará a sua potencial transferência para novos contextos de trabalho.

\section{Referências bibliográficas}

Alvesson, Mats (2002), Understanding Organizational Culture. London: Sage Publications.

Alvesson, Mats; Berg, Per Olof (1992), Corporate Culture and Organizational Symbolism. An Overview. Berlin / New York: Walter de Gruyter [1 ${ }^{a}$ edição].

Brembeck, Cole S. (1976), "Introducción", in Cole S. Brembeck; Timothy J.Thompson (orgs.), Nuevas estrategias para el desarrollo educativo: investigación intercultural de alternativas no formales. Buenos Aires: Editorial Guadalupe, 9-16.

Canário, Rui et al. (2002), Formação profissional contínua na administração local. Para uma orientação estratégica. Relatório retirado da internet <http://www.programaforal. gov.pt> em 11/11/2006.

Castagnos, Jean-Claude; Mouy, Philippe (1990), "Le nouveau statut de la formation dans la gestion des ressources humaines", Éducation Permanente, 104, 65-72.

Coombs, Philip H. (1968), La crise mondiale de l'éducation. Une analyse de systèmes. Paris: PUF. 
Coombs, Philip H. (1985), La crisis mundial en la educación. Perspectivas actuales. Madrid: Santillana.

Coombs, Philip H.; Ahmed, Manzoor (1975), La lucha contra la pobreza rural. El aporte de la educación no formal. Madrid: Editorial Tecnos.

Correia, José A. (1997), "Formação e trabalho: Contributos para uma transformação dos modos de os pensar na sua articulação”, in Rui Canário (org.), Formação e situações de trabalho. Porto: Porto Editora, 13-41.

Deal, Terence; Kennedy, Allan A. (1988), Corporate Cultures. The Rites and Rituals of Corporate Life. London: Penguin Books.

Dubar, Claude (1997a), “Formação, trabalho e identidades profissionais”, in Rui Canário (org.), Formação e situações de trabalho. Porto: Porto Editora, 43-52.

Dubar, Claude (1997b), A socialização. Construção das identidades sociais e profissionais. Porto: Porto Editora.

Dubar, Claude (2006), A crise das identidades. A interpretação de uma mutação. Porto: Edições Afrontamento.

Estanque, Elísio (2000), Entre a fábrica e a comunidade. Subjectividades e práticas de classe no operariado do calçado. Porto: Edições Afrontamento.

Estêvão, Carlos (org.) (2002), Training Policies and Practices in Organizations. Relatório de investigação. Braga: Centro de Estudos em Educação e Psicologia da Universidade do Minho.

Estêvão, Carlos et al. (orgs.) (2006), Políticas e práticas de formação em organizações empresariais portuguesas. Relato de uma investigação. Braga: Centro de Investigação em Educação do Instituto de Educação e Psicologia da Universidade do Minho.

Frost, Peter J. et al. (orgs.) (1991), Reframing Organizational Culture. London: Sage Publications.

Hofstede, Geert et al. (1990), "Measuring Organizational Cultures: A Qualitative and Quantitative Study Across Twenty Cases”, Administrative Science Quarterly, 35, 286-316.

La Belle, Thomas J. (1982), "Formal, Nonformal and Informal Education: A Holistic Perspective on Lifelong Learning”, International Review of Education, 28(2), 158-175.

La Belle, Thomas J.; Verhine, Robert E. (1975), “Education, Social Change, and Social Stratification", in Thomas J. La Bellle (org.), Educational Alternatives in Latin America. Los Angeles: UCLA Latin American Center Publications, 3-71.

Lesne, Marcel; Minvielle, Yvon (1988), “Socialisation et formation d'adultes”, Éducation Permanente, 92, 23-52.

Lima, Licínio C. (org.) (2004), Literacia(s) em contexto de trabalho. Investigação e educação/formação. Braga: Unidade de Educação de Adultos, Universidade do Minho.

Malglaive, Gérard (1988), "Les rapports entre savoir et pratique dans le développement des capacités d'apprentissage chez les adultes”, Éducation Permanente, 92, 53-61. 
Martin, Joanne; Meyerson, Debra (1988), "Organizational Culture and the Denial, Channelling and Acknowledgement of Ambiguity", in L. R. Pondy; R. J. Boland, Jr.; H. Thomas (orgs.), Managing Ambiguity and Change. New York: John Wiley, 93-125.

Martin, Joanne (1992), Cultures in Organizations: Three Perspectives. New York, Oxford: Oxford University Press / London: Sage Publications, 58-76.

Martin, Joanne (2002), Organizational Culture. Mapping the Terrain. London: Sage Publications.

Mehaut, Philippe (1990), “Les temps de l'entreprise et la formation”, Éducation Permanente, 104, 57-64.

Meyerson, Debra; Martin, Joanne (1987), "Cultural Change: An Integration of Three Different Views", Journal of Management Studies, 24, 623-647.

Ouchi, William G. (1986), Teoria Z. Como as empresas podem enfrentar o desafio japonês. São Paulo: Nobel [10 edição, tradução de Auriphelo Berrance Simões].

Palhares, José Augusto (2004), Jovens, experiência social e escutismo. Contributo para uma sociologia da educação não-escolar. Braga: Universidade do Minho [Dissertação de Doutoramento, na área de conhecimento de Sociologia da Educação - policopiado].

Paulston, Rolland G. (org.) (1972), Non-formal Education. An Annotated International Bibliography. New York / London: Praeger Publishers.

Peters, Thomas J.; Waterman, Robert H. (1987), Na senda da excelência. Lisboa: Publicações Dom Quixote [1 ${ }^{a}$ edição, tradução de J. Marques Henriques].

Rogers, Alan (2004), Non-Formal Education. Flexible Schooling or Participatory Education?. Hong Kong: The University of Hong Kong / Kluwer Academic Publishers.

Schein, Edgar H. (1985), Organizational Culture and Leadership. São Francisco: Jossey-Bass Publishers.

Specogna, Antonietta (2002), "L'Interprétation collective de consigne est-elle une situation d'apprentissage?”, Éducation Permanente, 151, 29-46.

Torres, Leonor L. (1997), Cultura organizacional escolar: representações dos professores numa escola portuguesa. Oeiras: Celta Editora.

Torres, Leonor L. (2001), "A cultura organizacional na (re)conceptualização da formação em contextos organizacionais”, Cadernos de Ciências Sociais, 21/22, 119-150.

Torres, Leonor L. (2004), Cultura organizacional em contexto educativo. Sedimentos culturais e processos de construção do simbólico numa escola secundária. Braga: Centro de Investigação em Educação da Universidade do Minho.

Trilla Bernet, Jaume (1998), La educación fuera de la escuela. Ámbitos no formales y educación social. Barcelona: Ariel [3. ${ }^{a}$ edição].

Verzat, Caroline (2002), "Le théâtre d'entreprise, entre développement personnel et changement organisationnel”, Éducation Permanente, 151, 159-170. 
120 | Leonor Lima Torres e José Augusto Palhares

Vincent, Guy (org.) (1994), L'éducation prisionnière de la forme scolaire? Scolarisation et socialisation dans les sociétés industrielles. Lyon: Presses Universitaires de Lyon. Wittorski, Richard (1997), "Évolution de la formation et transformation des compétences des formateurs", Éducation Permanente, 132, 59-72. 